Journal of Business and Management Research

ISSN: 2382-5219(Print); 2467-9267(Online)

July 2017, Vol.2, No.1 \& 2, pp.1-13

(C) 2017 Kathmandu University

School of Management

DOI: http://dx.doi.org/10.3126/jbmr.v2i1-2.18148

\title{
Trainee Characteristics and Transfer of Training: Effect of Supervisory Support (A Study of Public Managers in Nepal)
}

\author{
Seema Singh* \\ School of Management, Kathmandu University, Lalitpur, Nepal
}

\begin{abstract}
The significance of transfer of training to organizations has been recognized by researchers and managers alike, and the factors affecting the transfer have been the subject of many research studies in the West. Considering the recent growth in training investment and coverage in public enterprises in Nepal without corresponding impact on their performance, the issue of transfer of training has gained importance in our context. This study examines the effect of trainee characteristics, viz.: perceived content validity, learning transfer motivation, and self-efficacy on the level of training transfer and the role of supervisory support in this relationship in the context of Nepali public enterprises. Due to the non-availability of total population, the non-probability sampling method, specifically, quota sampling was used for selecting organizations, and then, managers meeting the pre-defined criteria, were selected for the study. Two hundred ninety-one officials from nine public enterprises participated in the survey. The findings suggest that level of transfer of training is moderate, and two trainee characteristics, viz.: learning transfer motivation and content validity, positively and significantly affect transfer of training whereas self-efficacy does not have such effect. Supervisory support moderates the relationship between content validity and transfer of training but not between learning transfer motivation and transfer of training. Managerial and research implications of the findings are discussed.
\end{abstract}

Keywords: Transfer of training, trainee characteristics, supervisory support, public enterprises, training

\section{Introduction}

Training transfer continues to be one of the most researched topics in the field of training and development. More specifically, factors related to transfer of learning from training to workplace have been the subject of various research studies, as they are important from the point of view of financial and strategic accountability of the learning function in most organizations for sustaining organizational competitiveness (Waltling \& Baeyer, 2003). Since line managers and supervisors are responsible for arranging appropriate and adequate training for their subordinates, it can be assumed that if they can ensure transfer environment for employees, application of learning would take place. In this context, it is important to understand how managerial and professional trainings can be made more effective so

* Author Email: seema@kusom.edu.np 
that organizations can gain competitive advantage through better managerial performance in competitive business environment.

Many studies have focused on various aspects of transfer of training and some of them have provided evidence of low transfer (e.g., Baldwin \& Ford, 1988; Kupritz, 2002). Therefore, it becomes necessary to identify factors which ensure transfer of training at a higher level. Scholars agree that the problem of transfer is related to training design, trainee characteristics, and the organizational characteristics (Cheng \& Hampson, 2008). However, little is known about the effect of work environment on transfer of training; for example, the effect of supervisory support is not well understood (Kazbour, McGee, Mooney, Masica, \& Brinkerhoff, 2013).

Baldin and Ford (1988) suggested that often there is problem of transfer of learning acquired through 'training' into sustained workplace performance, which is an issue faced by many organizations. It can be argued that the success of an enterprise should be assessed by its ability to do the job it was created for. Specifically, public enterprises have been established with multiple goals and responsibilities but most of them have difficulty functioning in an efficient manner and performing their assigned roles satisfactorily. One of the reasons behind this is lack of professionalism for the development of which they spend a huge amount from their budget as training and development activities (Mizell, 2010).

The status of Nepali public enterprises is not much different from this point of view. There is supportive government policy in respect of public enterprises which aims at making them peoplefriendly, dignified, accountable, and attractive by enhancing the skills of public managers. There are in-house training units in major public enterprises with substantial budgetary allocations for training activities (as stated in Policies and Programs of the Government of Nepal 2015).

Despite training-supportive policy measures, and structures and also huge expansion of training supply, the fact remains that the performance of public enterprises is not as expected. It is observed that most of the public enterprises have not been able to generate return on investment, pay dividend to government, and provide quality services to public. The overall analysis of public enterprises indicates that they have become a huge burden to the government with low return on investment, poor service quality, and limited range of delivery attributing to inefficient management (The Annual Performance Review of Public Enterprises, 2012). Most of them are operating at below optimal capacity, and are not able to compete with the private sector. This can at least partly be attributed to the inadequate transfer of training in public enterprises which has resulted in a situation of training not being instrumental in improving their performance level.

This study seeks to investigate the factors associated with training transfer, particularly individual trainee characteristics and supervisory support, among Nepali public managers in light of the poor transfer situation. More specifically, it aims to a. examine the effect of selected trainee characteristics on transfer of training among managers in Nepali public enterprises, and b. test the moderating effect of supervisory support on the way trainee characteristics influence transfer of training.

The study attempts to fill in, at least partly, the present gap in understanding the factors affecting transfer of training in Nepali public enterprises and provide some policy inputs for designing training interventions effectively to ensure greater transfer. The findings of this study would be helpful in creating enabling organizational conditions in public enterprises that support for improving training effectiveness. Selecting trainees with transfer-supportive personal characteristics would also be facilitated by the findings of this study. 


\section{Theoretical Background}

Past studies have identified a number of factors that influence training transfer. According to Baldwin and Ford (1988) three different factors - (1) trainee characteristics (ability, motivation to learn and transfer, self-efficacy and certain personality characteristics), (2) training design (principles of learning, goals, training content, its sequencing, similarity with actual job etc.), and (3) work environment (supervisor and colleague support, opportunity to use what has been learned) are the main antecedents of training transfer:.

\section{Trainee Characteristics}

Trainee characteristics influence training outcomes and hence a variety of trainees' characteristics have been examined in relation to the transfer of training (Simosi, 2012).They play a direct role in achieving training outcomes, and hence, to some degrees, transfer outcomes impacting various stages of training activities (Crisp, 2002).

\section{Perceived Content Validity}

The similarity of job requirements, instructional methods, aids, and equipment used in training and in an individual's work environment perceived by trainees also has its effect on transfer of training (Holton, Bates, \& Ruona, 2000). Perceived content validity is positively associated with transfer of training and ensures high positive transfer (Baldwin \& Ford, 1988).

Learning Transfer Motivation

An individual's level of training motivation is the key determinant of training effectiveness (Mathieu \& Martineau, 1997). It refers to the direction, intensity and persistence of effort toward utilizing the learning in a work setting (Holton et al., 2000).

Facteau, Dobbins, Ladd and Kudisch (1995) have argued for the importance of learning transfer motivation to the extent that they argue, the more motivated the trainees are, the more likely they would reap the intended benefits from the training experience, keeping everything else constant. Therefore, it can be assumed that the more attention to training motivation given, the more transfer will be assured.

Openness to Experience

The willingness to invest energy to change, providing support to individuals who use new techniques learned in the training is termed as openness to experience (Yamkovenko \& Holton, 2009). It is evident from studies that individuals open to experience respond better to learning situations and tend to be more open to trying new things, therefore they may be more prone to transfer (Yamkovenko \& Holton, 2009).

\section{Self-efficacy}

An individual's general belief that they are able to change their performance when they want to, is defined as self-efficacy (Holton et al, 2000). It explains the extent to which individuals feel confident and self-assured about applying new abilities in their jobs and can overcome obstacles that hinder the use of new knowledge and skills (Holton et al, 2000). Several studies have demonstrated that interventions designed to increase trainees' self-efficacy leads to transfer of training (e.g., Latham \& 
Budworth, 2006). Simosi (2012) argues that the generative capability of individuals for using their learned skills into successful performance plays a motivational role. Similarly, Ford, Quinones, Sego and Sorra (1992) found that trainees high in self-efficacy are more likely to perform complex and difficult tasks which are the characteristics of achievement oriented work environment.

\section{Transfer of Training}

Baldwin and Ford (1988) defined transfer of training as "knowledge, skills, and attitudes learned from training that are generalized to the job context and maintained over time" (p. 346). According to Taylor and Chan (2005), training transfer is an important factor for evaluating the effectiveness of people. It is a complex process which depends upon the intent or motivation of the learner (trainee characteristics), the workplace environment including supervisory support (organizational environment and characteristics), and the instructional design and delivery features of the training program (Subedi, 2004). In view of the evidences of the effect of various individual characteristics on transfer of training, this study proposes the following hypotheses:

H1a: Perceived Content Validity of trainees positively and significantly affects Transfer of Training.

H1b: Learning Transfer Motivation positively and significantly affects Transfer of Training.

H1c: Perceived Openness to Experience positively and significantly affects Transfer of Training.

H1d: Perceived (performance) Self-Efficacy positively and significantly affects Transfer of Training.

\section{Supervisor's Support}

Baldwin and Ford (1988) suggested that any method of improving transfer that occurs before or after formal training takes place in the work environment. A supportive work environment induces higher levels of trainees' transfer initiative (Simosi, 2012). One major component of work environment is supervisor's support.

Supervisory support is the extent to which managers support and reinforce the use of learning onthe-job (Holton et al., 2000). A person is said to have received supervisory support if his/her supervisor gets involved in "clarifying performance expectations after training, identifying opportunities to apply new skills and knowledge, setting realistic goals based on training, working with individuals on problems encountered while applying new skills, and providing feedback when individuals successfully apply new abilities" (Broucker, 2007, p. 7). It also refers to the degree to which trainees' managers/supervisors emphasize the importance of attending training programs and the stress the application of training content to the job. With Supervisor Support, the trainees may be more motivated to practice skills, which in turn will increase transfer of learning.

Support is described as instrumental (e.g., creating opportunities and providing resources to facilitate the use of new skills and knowledge), informational (e.g., suggesting ways to perform workrelated tasks and integrate new skills), emotional (e.g., showing approval and confidence) and appraisal (e.g., providing feedback) for transfer of learning (Nijman \& Gelissen, 2011).

It has been established in literature that supervisor's support has direct influence on transfer of training, and other predictor variables like motivation to learn, cognitive ability, self-efficacy etc. (Williams, 2008; Blume, Baldwin, \& Huang, 2010). Pidd (2004) argued that researchers and 
practitioners need to focus on personal and situational factors that may interact to influence learning and transfer so as to fully understand training transfer and to design effective training programs. Not much study has been done to see the influence of supervisory support on relationship between such predictor variables and transfer of training. Therefore, this study has included supervisory support as moderating variable to see the relationship between trainee characteristics and transfer of training.

Therefore, the second set of hypotheses is:

H2a: Supervisor's Support moderates the effect of Content Validity on Transfer of Training.

H2b: Supervisor's Support moderates the effect of Learning Transfer Motivation on Transfer of Training.

H2c: Supervisor's Support moderates the effect of Openness to Experience on Transfer of Training.

H2d: Supervisor's Support moderates the effect of Self-Efficacy on Transfer of Training.

Based on the literature and intended study, the following is the theoretical framework for this research:

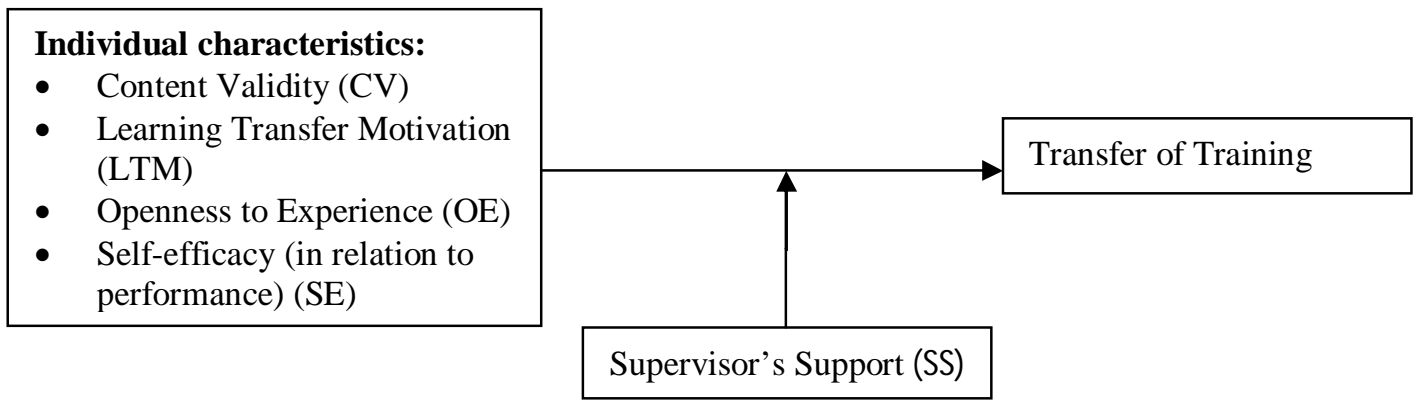

Figure 1.Conceptual Framework

\section{Methods}

\section{Population and Sample Design}

In Nepal there are currently in operation 37 public enterprises working in six sectors: industrial (seven), trading (six), service (seven), social (five), public utility (three), and financial (nine), (The Annual Performance Review of Public Enterprises, 2012). The theoretical population for this research was all public organizations (including both enterprises and regulatory body) of Nepal and the accessible population was limited to the employees working in Kathmandu, and also those managers who were involved in training in Kathmandu at the time of survey (only those who had two years' work experience and had participated at least in one of the training programs organized in-house). Due to the non-availability of total population, the non-probability sampling method was used to select the 
sample for the study. Non-probability sampling is described as those samples, which are not determined by chance, but rather by personal convenience, or judgment of the researcher.

Specifically, quota sampling method which is most sophisticated method in the non-probability sampling techniques was used; in the first stage the quotas or control categories of the population was developed, e.g., the quota from public sector would be such institutions which have their own training centers and hence budget allocation for the same is done. In the second-step, sampling of respondents was done. Accordingly, nine public enterprises were chosen as sample which met the criteria of inhouse training centers and budget as well as provision of in-house technical, managerial and professional trainings. For the selection of respondents the following criteria were used: managerial or officer level position, minimum two years' work experience in the same organization, participation in at least in one training of minimum three days' duration in the organization's own training center, and the training completion date at least six months before the survey.

Ninety self-reporting questionnaires were distributed to each organization, a total of 810, assuming that there would be 30 percent (of total questionnaires distributed) response rate which is accepted in behavioral research, i.e., 270 respondents which would allow us to generalize the findings to some extent. Altogether 357 completed questionnaires were collected out of which 291 were usable after checking with the defined criteria. The response rate was around $45 \%$, the usability rate being $36 \%$. The data was then analyzed for its normality, dispersion, and central tendency using descriptive statistics. Pearson Correlation and regression analysis were used for hypotheses testing.

The sources and definitions of variables for this study were taken as suggested by Holton et al. (2000). For trainee characteristics, the four constructs, viz.: Openness to Experience and Self-Efficacy (personality factors) as well as Learning Transfer Motivation and Content Validity (cognitive factors) were selected whereas for organizational factor, Supervisory Support, was selected from their validated instrument. For Transfer of Training construct, Xiao's (1996) instrument was used.

The study constructs were measured using self-reported perceptual data from the perspective of trainees. This process was used as it gives easy access to respondents and the instrument is also accepted with ease. While acknowledging limitations of self-reporting data, use of the same for this study has value for several reasons. For example, the use of self-report data in the collection of transfer system data is consistent with a key assumption underlying the development of Learning Transfer System Inventory which was designed to measure individual perceptions of transfer system constructs. Self-reports of these factors were valuable because of the fact very little is known about the nature of transfer systems in the Nepali public sector context, and these data provided one of the first views of psychologically meaningful transfer related factors operating in this context. Much of the literature review on environment and context clearly demonstrates that perception alone is enough to influence transfer of training (Crisp, 2002), since transfer intention is a result of employees' perception about self and environment. The instrument for this study consisted of 31items using 5-point Likert scale for measurement.

\section{Results}

In terms of the demographic profile of the respondents, three fourth of the respondents were males. The age distribution was between age 25 to above 60 years, maximum number $(67.4 \%)$ representing age group 31 to 40 years. The job tenure ranged from less than three years to more than 12 years, with 
the maximum number of respondents having job tenure between three to nine years (70.8\%). Majority $(70 \%)$ of them were officer level employees.

All the scales were found reliable except for Openness to Experience scale with reliability score less than 0.6 even after deleting two items (0.57), and hence it was dropped from further analysis.

The results indicate that the two trainee characteristics, viz.: Learning Transfer Motivation (LTM) and Self Efficacy (SE) were perceived at fairly higher level, with mean values 3.93 and 3.82 respectively. Content Validity (CV) had slightly below average mean (2.95), suggesting that it was perceived to have relatively low presence. Similarly, Supervisory Support (SS) as an organizational characteristic influencing training transfer was perceived slightly below average (2.94) suggesting that the support from supervisors for transfer of training was only moderately available. The mean value of the outcome variable, i.e., Training Transfer (TT), was slightly above (3.12), which indicates that the public enterprise managers perceive only moderate level of transfer of training.

Pearson correlation coefficients were computed for the study variables. The results of the correlational analyses are presented in Table 1, which show that all the relationships between the three trainee characteristics and Training Transfer as well as between Supervisory Support and Training Transfer were positive and statistically significant.

Table 1

Correlation Coefficients between Different Study Variables

\begin{tabular}{llrrrrrr}
\hline & & Mean & SD & 1 & 2 & 3 & 4 \\
\hline 1 & LTM & 3.93 & 0.60 & & & & \\
2 & SE & 3.82 & 0.57 & $.39 * *$ & & & \\
3 & CV & 3.11 & 0.60 & $.45^{* *}$ & $.18^{* *}$ & & \\
4 & SS & 2.94 & 0.61 & $.24^{* *}$ & $.11^{*}$ & $.31^{* *}$ & \\
5 & TT & 3.12 & 0.65 & $.48^{* *}$ & $.19^{* *}$ & $.51^{* *}$ & $.30^{* *}$ \\
\hline
\end{tabular}

Note: $* p<.10, * * p<.05$

LTM-Learning transfer motivation, SE-Self efficacy, CV-Content validity, SS-Supervisor support, TTTransfer of training

For a more robust test of the hypothesized effects of the predictor variables as well as their combined contributions to the outcome variable, i.e. Training Transfer, hierarchical regression analyses were performed. While estimating regression equations, in the first step control variables (job tenure, position, functional role, gender, education, and age) were introduced. In the second step the predictor variables (Learning Transfer Motivation, Content Validity and Self-Efficacy), and outcome variable (Transfer of Training) were included. Results are shown in Table 2.

Both models (demographic variables with TT, and predictor variables (LTM and CV) with TT were found to be significant with $F=3.91$ and 14.73 having $p<0.01$ (see Table 2). Though correlation analysis suggested that all three predictor variables were positively associated with Transfer of Training, regression results revealed that Learning Transfer Motivation and Content Validity significantly affected Transfer of Training. However, Self-Efficacy was not a significant determinant of Transfer of Training. Hence H1a and H1b were supported, but H1d was not. 
Table 2

Hierarchical Regression Analysis: Demographic, predictor and outcome variables

\begin{tabular}{lrr}
\hline & $\beta$ (Standardized Coefficients) & Step II \\
\hline Variables & Step I & 0.08 \\
\hline Job Tenure & $0.16^{* * *}$ & 0.05 \\
Position & 0.06 & $-0.04^{*}$ \\
Functional Role & $-0.14 * * *$ & -0.01 \\
Gender & -0.01 & 0.08 \\
Education & $0.13^{* *}$ & 0.00 \\
Age & 0.08 & $0.28^{* * *}$ \\
Learning Transfer Motivation & & -0.02 \\
Self-Efficacy & & $0.33^{* * *}$ \\
Content Validity & & $14.73 * * *$ \\
$F$ & $3.91 * * *$ & 0.33 \\
$R^{2}$ & 0.08 & \\
\hline
\end{tabular}

Note: $* p<.10, * * p<.05, * * * p<.01$

Table 3

Hierarchical Regression Analysis for Testing Hypotheses 2a, $2 b$

\begin{tabular}{lrrr}
\hline & \multicolumn{3}{c}{$\beta$ Standardized } \\
\hline Variables & Step I & Step II & Step III \\
\hline Job tenure & $0.16^{* *}$ & 0.08 & 0.09 \\
Position & 0.05 & 0.04 & 0.04 \\
Functional role & $-0.15^{* * *}$ & $-0.09^{*}$ & -0.08 \\
Gender & -0.02 & -0.02 & -0.02 \\
Education & $0.12^{* *}$ & $0.08^{*}$ & $0.08^{*}$ \\
Age & 0.08 & 0.01 & -0.01 \\
Learning transfer motivation (LTM) & & $0.26^{* * *}$ & 0.36 \\
Content validity (CV) & & $0.30^{* * *}$ & -0.14 \\
Supervisor support (SS) & & $0.14^{* * *}$ & -0.20 \\
LTM_SS & & & -0.19 \\
CV_SS & & & $0.77^{*}$ \\
& & & $13.71^{* * *}$ \\
$R^{2}$ & $3.86^{* * *}$ & $16.30^{* * *}$ & 0.36 \\
\hline
\end{tabular}

Note: $* p<.10, * * p<.05, * * * p<.01$

Moderating effect of Supervisory Support on the relationships between (i) Learning Transfer Motivation and Transfer of Training, and (ii) Content Validity and Transfer of Training were tested using Hierarchical Regression Analysis. Since the direct relationship between Self-Efficacy with Transfer of Training could not be established, moderating effect of Supervisory Support on the 
relationship between Self-Efficacy and Transfer of Training was not tested. The results showed that Supervisory Support moderated the relationship between Content Validity and Transfer of Training, but not between Learning Transfer Motivation and Transfer of Training. Table 3 summarizes the result of moderating effects on the predictor and outcome variables.

\section{Discussion}

The basic purpose of the study was to examine the relationship between trainee characteristics and transfer of training in Nepali public organizations and assess the moderating effect of supervisory support on this relationship.

The results show that there is a moderate level of perceived transfer of training in these organizations, which supports the basic argument of this study. The mean value of perceived transfer, which is 3.12 on a scale of 5 is, however, higher than generally assumed. One of the possible explanations for this could be the psychological desire of the respondents of not being seen as ineffective in utilizing learned skills and knowledge on the job. There might have been an obvious self-rating bias of over-estimating transfer behavior. There is an absence of standards for post-training improvements in performance behaviors of employees in Nepali public enterprises which might leave space for perceiving their performances in more positive sense as compared to actual performance level.

The findings suggest that the two trainee characteristics, viz.: Content Validity and Learning Transfer Motivation of trainees, significantly and positively influence transfer of training behavior. These finding are consistent with other research works that found motivation to transfer and transfer outcomes (e.g., Chiaburu, Van-dan \& Hutchins, 2010) as being positively and significantly associated.

Similarly, the relationship between Content Validity and Transfer of Training has been found to be affected by Supervisory Support which supports findings of other studies. However, the findings of the effect of Supervisory Support on relationship between Learning Transfer Motivation and Transfer of Training are not in line with the available existing literature. One study has, though, reported that perceived support from administrators during the post- training phase was not as influential to trainees who demonstrated higher learning impact (Futris, Schramm, Richardson \& Lee, 2015).

One of the possible explanations for Learning Transfer Motivation and Transfer of Training not being moderated by Supervisory Support could be the way training is designed and delivered in Nepali public enterprises. As there is not much preparation done prior to offering training in terms of the active involvement of the trainees in, for example, conducting needs assessment or sharing supervisory feedback both prior to and after the training event, they don't see much relevance of supervisor's support; rather they participate because of their own willingness or lack of it.

Organization policies, reward systems, and managerial behavior are the key factors which determine perception about training and its transfer in workplace as they attach meaning to it on the basis of their own values, beliefs, needs, and other individual characteristics which are positively correlated with performance enhancement (Tracey, Tannenbaum, \& Kavanagh, 1995). These are supposed to be facilitated by supervisors for the employees, but in this context, specifically in the public sector, it is observed that supervisors are not much concerned about and involved in subordinates' learning and transfer since development of their staff is not their core agenda. That is why both pre- and post-training associations of supervisor are very limited. 
While prior research has demonstrated that work environment factors (e.g., Supervisor Support) are also critical determinants of training transfer (Blume, Ford, Baldwing, \& Huang, 2010), it was participants' motivational factors that accounted for most of the unique variance influencing their transfer. Development level of trainees and need of supervisory support may vary-- highly experienced ones might not require that much of supervisory support-- they could be self-motivated as they are accountable to certain results, whereas, relatively new employees might require more support (emotional, informational, instrumental and appraisal) as suggested by Futris et al.(2015).

\section{Implications and Directions for Future Research}

HR managers have critical role in developing competitive advantage by improving in intangible assets and human capital through training, which helps employees maintain and support the organization strategy and goals (Noe, 2010). Although transfer of training sounds like something to be considered after training occurs, managers need to plan for before the training activities as well, in order to ensure conditions that facilitate transfer, e.g., to motivate trainees to attend a training program and to communicate about the program emphasizing the benefit of the training (Noe \& Kodwani, 2013).

Since the findings have suggested that there is direct link of Learning Transfer Motivation and Content Validity with Transfer of Training, it implies that managers have to design training packages in such a way that the trainees perceive relevance of training and its transfer in their actual workplace. During training also, the learning environment needs to be similar, as far as possible, to the one the trainees are used to and experience in their workplace. The work context and training context similarity would help in ensuring positive perception about the training content. If the trainees are involved in the process of identifying the training needs, they would perceive positively with the Content Validity and this will further motivate them to participate in the training and then transfer their learning in workplace.

This study has found that Learning Transfer Motivation has positive effect on Transfer of Training. Hence managers need to ensure such work environment which motivates trainees to participate in training and to transfer their learning. This implies that managers need to acknowledge the employees who transfer their learning at workplace and enhance performance of their unit, particularly reflecting on their performance appraisal and career growth.

Since Supervisor's Support affects the relationship between Content Validity and Transfer of Training, HR managers also need to provide training to supervisors on supervision function and its mechanisms such that they can be instrumental in providing support to trainees, which in turn would help trainees perceive training package (Content Validity) as a tool for better performance. It enhances their performance motivation. The supervisors themselves need to be motivated to develop their subordinates. They need to be seen as actively participating in the whole process of training programs.

In order to provide Supervisor Support to enhance transfer, they can communicate expectations to trainees as well as provide the encouragement and resources needed to apply training on the job. Employees, when they believe that new skills will help them effectively perform on-the-job, will be

motivated to participate and transfer it on the job. They can be oriented for this from the beginning of their job itself (culture of learning). 
Though Supervisory Support is not seen as moderating between Learning Transfer Motivation and Transfer of Training, there is a direct positive relationship between Learning Transfer Motivation and Training Transfer. Therefore, supervisors cannot ignore the criticality of Learning Transfer Motivation on Transfer of Training. They should ensure Learning Transfer Motivation in employees.

Various research implications can be derived for future study. Although large number of studies have examined the role of training transfer climate in employees' decision to make use on the job of what has been learned in training, only few studies have examined the role of other aspects of training transfer such as learning orientation, organization culture, structure etc. Studies on these issues would be required as it is also necessary to understand various antecedents and consequences of successful transfer of training in the workplace. Hence, research in this area could be a logical extension in future, building on the findings of this study. Study at the organizational level, examining the impact of organizational support on transfer of learning, could be another area of interest for researchers, using objective data rather than perceptual data. Similarly, examining both the extent and form of support provided (i.e., instrumental, informational, emotional and appraisal) from multiple perspectives, including the trainees' supervisors could enrich understanding of transfer of training in our context. This would provide a better understanding of what forms of support are most strongly associated with transfer of training. There is a need for looking at transfer of training from customers' perspective (Lai, 2006).

The findings of this research can be generalized to some extent with caution as the sample size is not adequate. The present study was conducted using data from employees only, not their supervisors, which may limit the generalizability of the results as transfer of training needs to be verified by the supervisor as well. Since supervisors are the best sources of data to measure transfer of training (Arthur et al., 2003), collecting data on transfer of training from supervisors can validate the transfer result.

\section{References}

Arthur Jr, W., Bennett Jr, W., Edens, P. S., \& Bell, S. T. (2003). Effectiveness of training in organizations: a meta-analysis of design and evaluation features. Journal of Applied Psychology, 88(2), 234-245. DOI: http://dx.doi.org/10.1037/0021-9010.88.2.234

Baldwin, T.T., \& Ford, J.K. (1988). Transfer of training: A review and directions for future research. Personnel Psychology, 41(4), 63-105. http://dx.doi.org/10.1111/j.1744-6570.1988.tb00632.x

Blume, B. D., Ford, J. K., Baldwin, T. T., \& Huang, J. L. (2010). Transfer of training: A meta-analytic review. Journal of Management, 36, 1065-1105. http://dx.doi.org/10.1177/0149206309352880

Broucker, B. (2007, September 19-22). Measuring transfer of public management programmes: The learning transfer system inventory in the Belgian federal administration. Paper presented at EGPA conference, Madrid, Spain.

Cheng, E. W., \& Hampson, I. (2008). Transfer of training: A review and new insights. International Journal of Management Reviews, 10(4), 327-341. http://dx.doi.org/10.1177/0149206309352880

Chiaburu, D. S., Van Dam, K., \& Hutchins, H. M. (2010). Social support in the workplace and training transfer: A longitudinal analysis. International Journal of Selection and Assessment, 18(2), 187200. http://dx.doi.org/10.1111/j.1468-2389.2010.00500.x 
Colquitt, J. A., LePine, J. A., \& Noe, R. A. (2000). Toward an integrative theory of training motivation: A meta-analytic path analysis of 20 years of research. Journal of Applied Psychology, 85(5), 678. http://dx.doi.org/10.1037/0021-9010.85.5.678

Crisp, J. (2002). Exploration of factors affecting transfer of training into the workplace: A case study of selected capacity building training courses in Western Australia (Doctoral dissertation). University of Queensland, Brisbane.

Facteau, J. D., Dobbins, G. H., Russell, J. E., Ladd, R. T., \& Kudisch, J. D. (1995). The influence of general perceptions of the training environment on pretraining motivation and perceived training transfer. Journal of Management, 21(1), 1-25.

Ford, J. K., Quiñones, M. A., Sego, D. J., \& Sorra, J. S. (1992). Factors affecting the opportunity to perform trained tasks on the job. Personnel Psychology, 45(3), 511-527.

Futris, T. G., Schramm, D. G., Richardson, E. W., \& Lee, T. K. (2015). The impact of organizational support on the transfer of learning to practice. Children and Youth Services Review, 51, 36-43. http://dx.doi.org/10.1016/j.childyouth.2015.01.019

Government of Nepal (2014). Office of the Prime Minister and Council of Ministers, policies and programmes of the government of Nepal for fiscal year 2071-72. Kathmandu: Author.

Holton, E. F., Bates, R. A., \& Ruona, W. E. (2000). Development of a generalized learning transfer system inventory. Human Resource Development Quarterly, 11(4), 333-360.

Kazbour, R. R., McGee, H. M., Mooney, T., Masica, L., \& Brinkerhoff, R. O. (2013). Evaluating the impact of a performance-based methodology on transfer of training. Performance Improvement Quarterly, 26(1), 5-33.

Kozlowski, S. W., \& Salas, E. (1997). A multilevel organizational systems approach for the implementation and transfer of training. Improving Training Effectiveness in Work Organizations, 247- 287.

Kupritz, V. W. (2002). The relative impact of workplace design on training transfer. Human Resource Development Quarterly, 13(4), 427-447.

Lai, J. Y. (2006). Assessment of employees' perceptions of service quality and satisfaction with ebusiness. International Journal of Human-Computer Studies, 926-938.

Latham, G. P., \& Budworth, M. H. (2006). The effect of training in verbal self-guidance on the selfefficacy and performance of Native North Americans in the selection interview. Journal of Vocational Behavior, 68(3), 516-523. http://dx.doi.org/10.1016/j.jvb.2005.11.005

Mathieu, J. E., \& Martineau, J. W. (1997). Individual and situational influences on training motivation. In J. K. Ford (Ed.), Improving training effectiveness in work organizations (pp. 193221). New York: Psychology Press.

Ministry of Finance (2012).Annual review of public enterprises. Kathmandu: Author.

Mizell, H. (2010). Why professional development matters, learning forward. Oxford: Learning Forward.

Nijman, D., \& Gelissen, J. (2011).Direct and indirect effects of supervisory support on transfer of training. In R.F. Poell, \& M. Van Woerkom (Eds.), Supporting workplace learning (pp. 89-106). Netherlands: Springer.

Noe, R. A. \& Kodwani, A.D. (2013). Employee training and development. New Delhi: McGraw Hill.

Noe, R. A. (2010). Employee training and development. Singapore: McGraw-Hills Education.

Pidd, K. (2004). The impact of workplace support and identity on training transfer: A case study of drug and alcohol safety training in Australia. International Journal of Training and Development, 8(4), 274-288. http://dx.doi.org/10.1111/j.1360-3736.2004.00214.x 
Simosi, M. (2012). The moderating role of self-efficacy in the organizational culture-training transfer relationship.International Journal of Training and Development, 16(2) 92-106. http://dx.doi.org/10.1111/j.1468-2419.2011.00396.x

Subedi, B. S. (2004). Emerging trends of research on transfer of learning. International Education Journal, 5(4), 591-599.

Taylor, P.J., Russ-Eft, D.F., Chan, D. W.L., (2005). A metaanalytic review of behavior modeling training. Journal of Applied Psychology. 90(4), 692-709. http://dx.doi.org/10.1037/00219010.90.4.692

Tracey, J. B., Tannenbaum, S. I., \& Kavanagh, M. J. (1995). Applying trained skills on the job: The importance of the work environment. Journal of Applied Psychology, 80(2), 239.

US Department of Health and Human Services (1999). A model for research on training effectiveness. Washington: Author.

Waltling, D., Prince, C. \& Beaver, G. (2003). University business schools 2 market: The changing dynamics of the corporate education market. Strategic Change, 12(4), 223-234.

Williams, D. J. (2008). An analysis of the factors affecting training transfer within the work environment (No.AFIT/GIR/ENV/08-M25). Air Force Institute of Tech Wright-Patterson Graduate School of Engineering and Management.

Xiao, J. (1996). The relationship between organizational factors and the transfer of training in the electronics industry in Shenzhen, China. Human Resource Development Quarterly, 7(1), 55-73. http://dx.doi.org/10.1002/hrdq.3920070107

Yamkovenko, B., \& Holton III, E. F. (2009).Towards a theoretical model of dispositional influences on transfer of learning. $10^{\text {th }}$ AHRD International Conference on Human Resource Development. 